\title{
SAP domain-dependent Mkl1 signaling stimulates proliferation and cell migration by induction of a distinct gene set indicative of poor prognosis in breast cancer patients
}

Irem Gurbuz ${ }^{1,2}$, Jacqueline Ferralli ${ }^{1}$, Tim Roloff ${ }^{1}$, Ruth Chiquet-Ehrismann ${ }^{1,2^{*}}$ and Maria B Asparuhova ${ }^{1}$

\begin{abstract}
Background: The main cause of death of breast cancer patients is not the primary tumor itself but the metastatic disease. Identifying breast cancer-specific signatures for metastasis and learning more about the nature of the genes involved in the metastatic process would 1) improve our understanding of the mechanisms of cancer progression and 2) reveal new therapeutic targets. Previous studies showed that the transcriptional regulator megakaryoblastic leukemia-1 (Mkl1) induces tenascin-C expression in normal and transformed mammary epithelial cells. Tenascin-C is known to be expressed in metastatic niches, is highly induced in cancer stroma and promotes breast cancer metastasis to the lung.
\end{abstract}

Methods: Using HC11 mammary epithelial cells overexpressing different Mkl1 constructs, we devised a subtractive transcript profiling screen to identify the mechanism by which Mkl1 induces a gene set co-regulated with tenascin-C. We performed computational analysis of the Mkl1 target genes and used cell biological experiments to confirm the effect of these gene products on cell behavior. To analyze whether this gene set is prognostic of accelerated cancer progression in human patients, we used the bioinformatics tool GOBO that allowed us to investigate a large breast tumor data set linked to patient data.

Results: We discovered a breast cancer-specific set of genes including tenascin-C, which is regulated by Mkl1 in a SAP domain-dependent, serum response factor-independent manner and is strongly implicated in cell proliferation, cell motility and cancer. Downregulation of this set of transcripts by overexpression of Mkl1 lacking the SAP domain inhibited cell growth and cell migration. Many of these genes are direct Mkl1 targets since their promoter-reporter constructs were induced by Mkl1 in a SAP domain-dependent manner. Transcripts, most strongly reduced in the absence of the SAP domain were mechanoresponsive. Finally, expression of this gene set is associated with high-proliferative poor-outcome classes in human breast cancer and a strongly reduced survival rate for patients independent of tumor grade.

Conclusions: This study highlights a crucial role for the transcriptional regulator Mkl1 and its SAP domain during breast cancer progression. We identified a novel gene set that correlates with bad prognosis and thus may help in deciding the rigor of therapy.

Keywords: Myocardin-related transcription factor-A (MRTF-A), Metastasis, Cancer progression, Prognosis, Gene regulation, Mechanical strain

\footnotetext{
* Correspondence: Ruth.Chiquet@fmi.ch

${ }^{1}$ Friedrich Miescher Institute for Biomedical Research, Maulbeerstrasse 66, Basel $\mathrm{CH}-4058$, Switzerland

${ }^{2}$ Faculty of Science, University of Basel, Klingelbergstrasse 50, Basel CH-4056,

Switzerland
} 


\section{Background}

Most breast cancer patients die from tumor metastases and not from the primary tumor itself. Thus, the identification of genes and signaling pathways influencing the metastatic process are of utmost importance. Once the mechanisms leading to metastasis are uncovered, they can in the future serve as a rational basis for prognosis and intervention. From the beginning of its discovery, tenascin- $C$ has been strongly associated with tumorigenesis and cancer progression in many different types of tumors (reviewed in $[1,2]$ ). Tenascin-C was not only enriched in breast cancer tissue [3,4], but its high expression was part of a gene signature of breast cancers metastasizing to the lung [5]. There is strong evidence that tenascin- $\mathrm{C}$ contributes to the metastatic behavior of breast cancer cells [6] by providing a niche for their settlement in the lung $[7,8]$. The source of tenascin- $\mathrm{C}$ can be the tumor cells themselves as well as the stromal cells of the cancer microenvironment. Downregulation of tenascin-C by miR-335 or shRNA in human cancer cells in a mouse xenograft model inhibits metastasis formation [7], and in tenascin-C-deficient mice, metastasis formation of tenascin- $\mathrm{C}$ positive cancer cells is also suppressed [9].

There are many signaling pathways inducing tenascin-C expression (reviewed in [10]). Among these, mechanical strain application in vivo as well as to cells in culture is a potent stimulus to induce tenascin- $\mathrm{C}$ expression in fibroblasts $[11,12]$. We have recently shown that induction of tenascin- $\mathrm{C}$ by cyclic mechanical strain requires the action of Mkl1 [13]. Mkl1 is a member of the myocardin-related transcription factor family (MRTF) and a well-known transcriptional co-activator of serum response factor (SRF) [14-16]. SRF target genes, which are regulated upon recruitment of MRTF cofactors, encode proteins involved in actin cytoskeletal function that can either be structural (for example, actin) or related to actin dynamics (for example, talin 1) (reviewed in $[17,18])$. However, Mkl1-mediated stretch-induced tenascin-C expression in fibroblasts did not require SRF, but instead depended on the potential DNAbinding SAP domain of Mkl1. This implies a novel mode of Mkl1 action as a bona fide transcription factor in mechanotransduction [13]. Interestingly, normal and transformed mouse mammary epithelial cells also appear to be highly sensitive to Mkl1 signaling, responding to Mkl1 overexpression with several fold induction of tenascin-C [13].

The present study was designed to find SAP-dependent Mkl1 target genes co-regulated with tenascin-C and to analyze whether such genes could be indicative of specific physiological states of cells that might be controlled by mechanotransduction. For our study, we made use of the HC11 mammary epithelial cell line. HC11 cells are capable of both self-renewal and differentiation and can be cultured for unlimited time in an undifferentiated state [19], the condition we used in our study. HC11 cells can reconstitute the ductal epithelium of a cleared mammary fat pad in vivo with ductal, alveolar and myoepithelial cells, illustrating their stem cell abilities $[19,20]$. In addition, HC11 cells contain a mutated p53 gene that not only increases the replicative potential of stem cells but confers predisposition to mammary carcinoma [21]. Undifferentiated $\mathrm{HC} 11$ cells share transcriptome signatures with human breast cancer [22], supporting the relevance of this model for breast cancer-related studies. We therefore concluded our study by investigating whether the genes co-regulated with tenascin- $\mathrm{C}$ would also be implicated in breast cancer progression.

\section{Results}

\section{Screen for SAP-dependent Mkl1 target genes}

We devised a screening method to identify genes coregulated with tenascin-C by Mkl1 in a SAP domaindependent manner without involvement of SRF. For this purpose, we used HC11 mammary epithelial cells that react strongly to the overexpression of Mkl1 with induction of tenascin-C expression [13]. We compared three $\mathrm{HC} 11$ strains that either overexpress the C-terminal red fluorescent protein (RFP)-tagged full length Mkl1 (HC11-FL), Mkl1-RFP with a mutated SRF-interaction site (HC11-mutB1) or Mkl1-RFP with a deletion of the SAP domain (HC11- $\triangle \mathrm{SAP}$ ). None of the three Mkl1 variants appear to be toxic to the cells, as we have not observed any changes in viability or cell morphology. HC11-FL cells were shown to overexpress Mkl1 7.1-fold above the endogenous Mkl1 present in parental HC11 cells [13], and were used as control cells in our study. All cell strains were FACS sorted to express similar levels of Mkl1-RFP proteins. These cells were used for transcript profiling and gene lists of interest were established as shown in Figure 1A, B. A scatter plot (Figure 1A) of all transcripts expressed in $\mathrm{HC} 11$-mutB1 versus HC11-FL control cells (y-axis) and all transcripts expressed in HC11- $\triangle \mathrm{SAP}$ versus HC11-FL control cells ( $\mathrm{x}$-axis) shows that a large majority of transcripts does not differ significantly between the three cell strains (log fold change $(F C) \approx 0$; black dots). Setting the threshold to a 2 -fold reduction ( $\log F C=-1$; grey lines), three gene sets can be distinguished: 1) blue dots represent genes that are lower in HC11-mutB1 than in HC11-FL control cells, but are unaffected in HC11- $\triangle$ SAP cells, thus representing typical SRF/Mkl1 target genes; 2) green dots represent genes that are lower in HC11- $\triangle \mathrm{SAP}$ than in HC11-FL control cells, but are unaffected in HC11-mutB1 cells (this gene set includes tenascin-C); and 3) red dots indicate genes with reduced expression in both HC11-mutB1 and HC11- $\triangle$ SAP cells compared to HC11-FL control cells. 


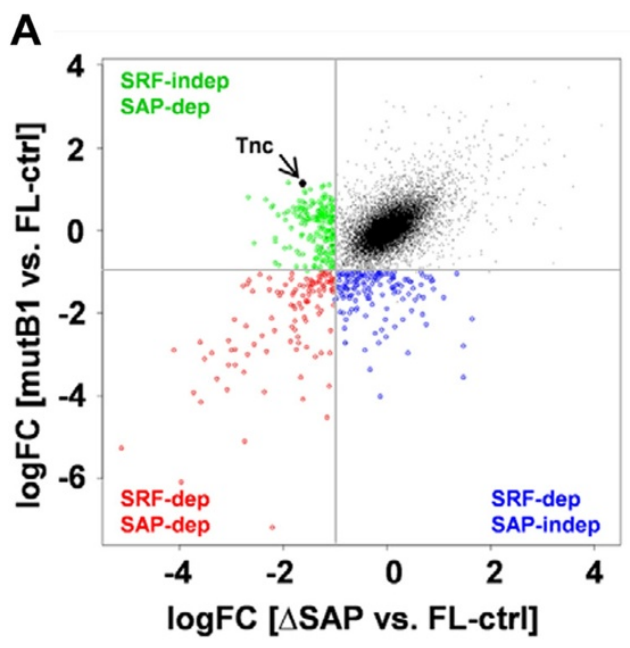

\section{Molecular and Cellular Functions (Ingenuity Systems ${ }^{\circledR}$ analysis)}

SRF-dep / SAP-indep

Cellular Movement

Cell-to-Cell Signaling \& Interaction

Cellular Growth \& Proliferation

Cellular Assembly \& Organization

Cell Morphology

Cell Cycle

Cell Death

Cellular Development

Post-Translational Modification

Protein Synthesis

DNA Replication \& Recombination

Protein Degradation

SRF-dep / SAP-dep

Post-Translational Modifications

Protein Degradation

Protein Synthesis

Cellular Growth \& Proliferation

Cellular Development

Cell Movement

Cell-to-Cell Signaling \& Interaction

Cell Morphology

Cellular Assembly \& Organization

Cell Cycle

DNA Replication \& Recombination

Cell Death

\section{SRF-indep / SAP-dep}

Cell Cycle

Cellular Assembly \& Organization

DNA Replication \& Recombination

Cellular Movement

Cellular Growth \& Proliferation

Cell Death

Cell Morphology

Cellular Development

Post-Translational Modifications

Cell-to-Cell Signaling \& Interaction
B

\section{>2-fold reduced in:}

mutB1 vs. FL-ctrl $\triangle S A P$ vs. FL-ctrl

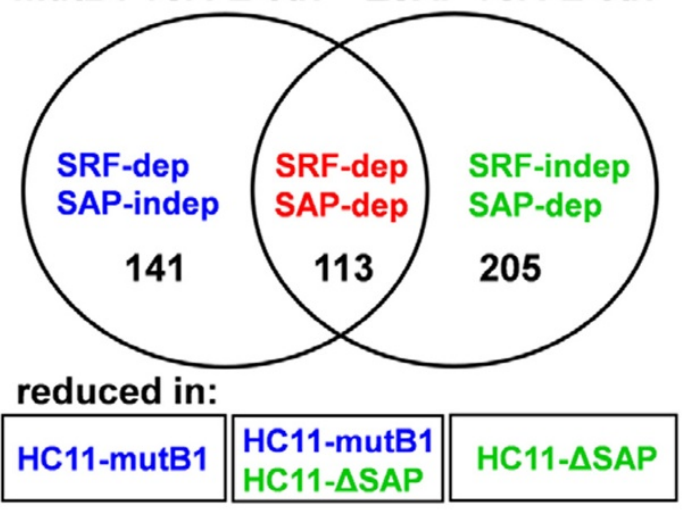

D

\section{Diseases and Disorders \\ (Ingenuity Systems ${ }^{\circledR}$ analysis)}

SRF-dep / SAP-indep

Connective Tissue Disorders Inflammatory Disease

Skeletal \& Muscle Disorders

Cancer

Inflammatory Response

Genetic Disorder

Cardiovascular Disease

Organismal Injury \& Abnormalities

Infectious Disease

Metabolic Disease

Developmental Disorder

Hematological Disease

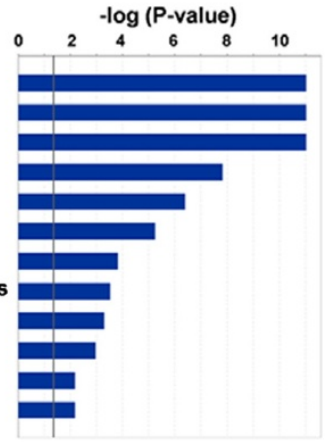

SRF-dep / SAP-dep

Cancer

Inflammatory Response

Connective Tissue Disorders

Cellular Growth \& Proliferation

Genetic Disorders

Cardiovascular Disease

Skeletal \& Muscle Disorders

Organismal Injury \& Abnormalities

Hematological Disease

Metabolic Disease

Developmental Disorder

Inflammatory Disease

$\log$ (P-value)

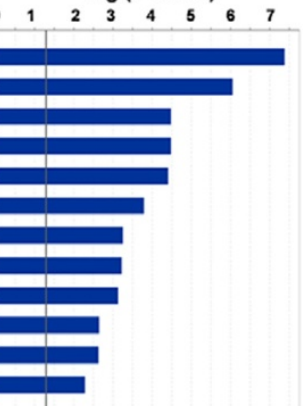

SRF-indep / SAP-dep

Cancer

Genetic Disorder

Skeletal \& Muscle Disorders

Hematological Disease

Infectious Disease

Inflammatory Disease

Developmental Disorder

Organismal Injury \& Abnormalities

Cardiovascular Disease

Connective Tissue Disorders

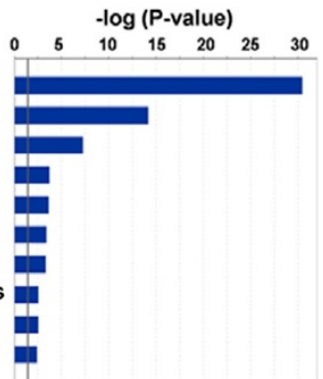

Figure 1 (See legend on next page.) 
(See figure on previous page.)

Figure 1 Screen for SAP-dependent Mkl1 target genes and their implication in cancer. (A) Scatter plot and (B) Venn diagram representing classification of Mkl1 target genes into three groups: SRF-dependent/SAP-independent (blue), SRF-dependent/SAP-dependent (red) and SRF-independent/SAP-dependent (green). The scatter plot (A) represents the log fold change (logFC) in gene expression in HC11- $\triangle S A P$ versus HC11-FL control cells (x-axis; $\triangle S A P$ vs. FL) and between HC11-mutB1 versus HC11-FL control cells (y-axis; mutB1 vs. FL). Each dot represents a probeset, and the one for tenascin-C is highlighted (TnC). The vertical and horizontal lines in the chart denote the 2-fold change cutoff (logFC $=-1$ ). The Venn diagram (B) represents the number of probesets for transcripts, which are more than 2-fold reduced in either HC11-mutB1 or HC11- $\triangle$ SAP cells when compared to HC11-FL control cells. Boxes below the Venn diagram indicate the cell strains that have reduced levels of the respective transcripts. (C, D) Functional analysis for the three Mkl1-regulated gene sets performed using the IPA software. The high-level functional (C) and disease (D) categories are displayed along the x-axis of each bar chart. The $y$-axis displays the -log of the P-value determined by right-tailed Fisher's exact test. The P-value is a measure of the likelihood that the association between a set of genes in each dataset and a related function or disease is due to random association. The grey vertical line denotes the cutoff for significance $(\mathrm{P}=0.05 ;-\mathrm{log} P=1.3)$.

Thus, this approach enabled us to form three gene sets that were distinct from the large majority of transcripts and were dependent for expression on the B1 site of Mkl1, the SAP domain, or both. The three groups presented by a Venn diagram (Figure 1B) contain 141 probesets for transcripts that depended on the function of the B1 site but not the SAP domain for their induction, 113 probesets for transcripts that depended on both of these Mkl1 domains and a third group of 205 probesets for transcripts co-regulated with tenascin- $C$ that did not require an interaction of Mkl1 with SRF but depended on the SAP domain for induction (complete probeset lists and annotations are found in Additional file 1: Table S1, Additional file 2: Table S2 and Additional file 3: Table S3). This analysis revealed that the SAP-dependent mechanism of tenascin- $C$ regulation by Mkl1 is shared by a large cohort of genes. Below the Venn diagram, we indicated which cells were deficient in the respective transcripts. Thus, the typical SRF/Mkl1 target genes are reduced in HC11-mutB1 cells, while the SRF-independent/ SAP-dependent genes are reduced in HC11- $\triangle$ SAP cells. The intermediate group that requires both Mkl1 activities is reduced in both the HC11-mutB1 and HC11- $\triangle \mathrm{SAP}$ cells.

\section{The SAP-dependent Mkl1 target genes are implicated in cancer}

Functional analysis of the three gene lists using the IPA software revealed different molecular and cellular functions (Figure 1C) and different disease associations (Figure 1D) for the three types of gene signatures. Thus, the SRF-dependent/SAP-independent signature implicated a function of these genes in cellular movement and the linked diseases included connective tissue disorders, inflammatory disease and skeletal and muscle disorders, which are the main features known to be regulated by SRF/Mkl1 interaction [23-25]. The SRF-dependent/SAPdependent group of genes includes as major functions post-translational modification, protein degradation and protein synthesis, and the top disease association is cancer. Finally, the genes of the SRF-independent/SAP-dependent group were associated with extremely high significance with cell cycle and cancer $(-\log \mathrm{P} \geq 25$ and $\geq 30$, respectively), while the SRF/Mkl1 target genes were associated with the same two categories at low significance only $(-\log \mathrm{P} \geq 2$ and $\geq 7$, respectively). These data imply that SAP-dependent induction of transcription by Mkl1 may counteract the known differentiation-promoting effect of SRF/Mkl1-induced transcription. A list of SAP-dependent genes with published cancer-related functions, whose transcripts were downregulated more than 3-fold in HC11- $\triangle$ SAP compared to HC11-FL control cells, is presented in Table 1. To confirm that these transcripts are indeed differentially expressed in the different $\mathrm{HC} 11$ cell strains, qRT-PCR analysis was performed using cDNA from three different batches of the respective HC11 strains. Differences in gene expression between HC11- $\triangle$ SAP and control cells are presented in Table 1 and in more detail in Additional file 4: Figure S1. The qRT-PCR results agreed with the data obtained by transcript profiling. We also tested the SAP-dependent gene expression in the $\mathrm{HC} 11$ strains when grown in the presence of serum. It is interesting to note that in the presence of $3 \%$ FCS, these transcripts remained strongly reduced in HC11- $\triangle$ SAP compared to control cells (Table 1). Thus, the induction of these genes seems to depend mainly on whether the SAP domain is present in the transfected Mkl1 construct.

In addition, we monitored changes in the expression of some of the SRF-independent/SAP-dependent Mkl1 targets on a protein level. In agreement with the changes seen at the transcript level, we confirmed the reduction of tenascin-C, Wisp1 and Nox4 proteins in cells overexpressing the $\triangle$ SAP-Mkl1 construct compared to the HC11-FL control and HC11-mutB1 cells (Additional file 4: Figure S2). Using zymography, we found that Mmp2, a gene that was not affected by Mkl1 overexpression at the transcript level was highly expressed in all three cell strains, whereas Mmp3 and/or 12, which belonged to the SRF-dependent/SAP-dependent gene set, were almost completely lacking in HC11-mutB1 as well as HC11- $\triangle$ SAP cells, corresponding to the data obtained by transcript profiling. 
Table 1 SAP-dependent Mkl1 target genes

\begin{tabular}{|c|c|c|c|c|c|}
\hline \multirow[t]{2}{*}{ Gene } & \multirow[t]{2}{*}{ Description } & \multicolumn{3}{|c|}{$\begin{array}{l}\text { Fold Reduction in } \\
\text { HC11- } \triangle \text { SAP vs. HC11-FL cells }\end{array}$} & \multirow[t]{2}{*}{ Functions } \\
\hline & & $\begin{array}{l}\text { Microarrays } \\
\text { in } 0.03 \% \text { FCS }\end{array}$ & $\begin{array}{l}\text { qRT-PCR in } \\
0.03 \% \text { FCS }\end{array}$ & $\begin{array}{l}\text { qRT-PCR } \\
\text { in } 3 \% \text { FCS }\end{array}$ & \\
\hline \multicolumn{6}{|c|}{ SRF-independent genes } \\
\hline Tnc & Tenascin C, ECM protein & $3.07^{* * *}$ & $3.50^{* * *}$ & $26.34^{* * *}$ & $\begin{array}{l}\text { Cell adhesion, cell migration, wound healing and tissue } \\
\text { remodeling, cancer cell invasion and metastasis [10] }\end{array}$ \\
\hline Anln & Anillin, actin binding protein & $3.10^{* * *}$ & $1.93^{* * *}$ & $1.38^{* *}$ & $\begin{array}{c}\text { Cell cycle regulation [26], cell motility and cancer } \\
\text { progression [26-28] }\end{array}$ \\
\hline Nox4 & NADPH oxidase 4 & $3.31^{* * *}$ & $94.19^{* *}$ & $332.70^{* * *}$ & $\begin{array}{c}\text { Cell growth, differentiation and migration [29], tumor } \\
\text { angiogenesis [30] }\end{array}$ \\
\hline Adamts16 & Metallopeptidase, ECM protein & $3.63^{* * *}$ & $5.70^{* * *}$ & $14.84^{* *}$ & $\begin{array}{l}\text { Cell growth and motility [31], role in arthritis [32] and cancer } \\
\text { [31] }\end{array}$ \\
\hline Krt5 & $\begin{array}{c}\text { Keratin } 5 \text {, intermediate filament } \\
\text { protein }\end{array}$ & $3.73^{* * *}$ & $2.74^{* * *}$ & $8.02^{* * *}$ & $\begin{array}{c}\text { Protein synthesis, epithelial cell growth and } \\
\text { differentiation }[33,34]\end{array}$ \\
\hline p15 (PAF) & $\begin{array}{l}\text { 2810417H13Rik, } \\
\text { PCNA-associated factor }\end{array}$ & $3.91^{* * *}$ & $1.89^{* * *}$ & $1.34^{* * *}$ & $\begin{array}{l}\text { DNA repair and cell cycle regulation, cell survival and } \\
\text { proliferation, tumorigenesis [35-37], hematopoiesis [38] }\end{array}$ \\
\hline Ass1 & Argininosuccinate synthetase 1 & $4.23^{* * *}$ & $3.89^{* *}$ & $2.72^{* *}$ & Regulation of nitric oxide production and cell viability $[39,40]$ \\
\hline Cd34 & CD34 antigen, stem cell antigen & $4.25^{* * *}$ & $10.61^{* * *}$ & $1.72^{* * *}$ & Vessel development and function [41], tumor growth $[42,43]$ \\
\hline Wisp1 & $\begin{array}{l}\text { WNT1 inducible signaling } \\
\text { pathway protein 1, ECM protein }\end{array}$ & $4.41^{* * *}$ & $2.54^{* *}$ & $4.06^{* *}$ & $\begin{array}{c}\text { Cell proliferation and survival, ECM deposition and turnover, } \\
\text { EMT, tumorigenesis, tissue remodeling [44] }\end{array}$ \\
\hline Mcm6 & $\begin{array}{l}\text { Minichromosome maintenance } \\
\text { complex component } 6\end{array}$ & $4.42^{* * *}$ & $2.83^{* * *}$ & $1.30^{* * *}$ & Cell cycle regulation [45] \\
\hline Car12 & Carbonic anyhydrase 12 & $4.58^{* * *}$ & $16.11^{* * *}$ & $26.07^{* *}$ & $\begin{array}{l}\text { Cell survival under hypoxic conditions, tumor-associated cell } \\
\text { migration and invasion }[46,47]\end{array}$ \\
\hline Htatip2 & $\begin{array}{l}\text { Hyaluronectin, TIP30, } \\
\text { transcriptional regulator }\end{array}$ & $5.89^{* * *}$ & $548.59^{* * *}$ & $245.27^{* * *}$ & $\begin{array}{l}\text { Regulation of apoptosis [48], tumor growth and } \\
\text { metastasis [49] }\end{array}$ \\
\hline Kif26b & Kinesin family member $26 \mathrm{~B}$ & $6.33^{* * *}$ & $8.36^{* * *}$ & $61.22^{* * *}$ & $\begin{array}{l}\text { Regulation of adhesion and cell polarity in kidney } \\
\text { development [50] }\end{array}$ \\
\hline \multicolumn{6}{|c|}{ SRF-dependent genes } \\
\hline Lox & Lysyl oxidase, ECM protein & $4.61^{* * *}$ & $4.70^{* *}$ & $12.04^{* * *}$ & $\begin{array}{l}\text { ECM turnover, connective tissue remodeling and repair, } \\
\text { tumor progression and metastasis }[51,52]\end{array}$ \\
\hline Mmp12 & $\begin{array}{l}\text { Matrix metallopeptidase } 12, \\
\text { metalloelastase }\end{array}$ & $12.01^{* * *}$ & $23.49^{* * *}$ & $4.90^{* *}$ & $\begin{array}{l}\text { ECM degradation in tissue remodeling [49] and } \\
\text { tumorigenesis [53] }\end{array}$ \\
\hline Mmp3 & $\begin{array}{l}\text { Matrix metallopeptidase } 3 \text {, } \\
\text { stromelysin-1 }\end{array}$ & $15.64^{* * *}$ & $14.70^{* * *}$ & $2.08^{* *}$ & $\begin{array}{l}\text { ECM degradation in tissue remodeling [49] and } \\
\text { tumorigenesis [54] }\end{array}$ \\
\hline
\end{tabular}

Abbreviations: ECM extracellular matrix protein, PCNA proliferating cell nuclear antigen, EMT epithelial-to-mesenchymal transition.

${ }^{* * * P}<0.001,{ }^{* *} \mathrm{P}<0.01$, Student's $t$ test.

\section{SRF-independent/SAP-dependent transcripts represent direct Mkl1 target genes}

Since we have previously shown that the SAP domain of Mkl1 interacts with the proximal promoter of tenascin-C to induce its transcription [13], we tested whether this was also the case for other transcripts of the same group. The promoters of the SRF-independent/SAP-dependent genes listed in Table 1 encompassing at least 500 bp upstream of the transcription start site (TSS) were fused to the secreted alkaline phosphatase (SEAP) reporter gene of pSEAP2-Basic. We tested the induction of each promoter-reporter construct by co-transfection with FLMkl1 (Figure 2A). This revealed that the majority of the new promoters tested ( 8 out of 12) were induced at least 2 -fold by Mkl1 in comparison to co-transfection with an inactive Mkl1 devoid of the transactivation domain, indicating that these are indeed direct Mkl1 target genes. The promoter constructs that did not respond to Mkl1 overexpression may represent genes that are indirectly regulated by $\mathrm{Mkl1}$, or the relevant promoter regions were not contained in the constructs tested. Next, we investigated whether the induction was SAPdependent and SRF-independent by comparing the reporter activity after co-transfection with mutB1- versus $\triangle \mathrm{SAP}-\mathrm{Mkl1}$ variants (Figure $2 \mathrm{~B}$ ). Indeed, the promoterreporter constructs induced by FL-Mkl1 were also strongly induced by mutB1-Mkl1, but not by $\triangle$ SAP-Mkl1. In contrast, the promoter construct for Acta2, a gene from the SRF-dependent/SAP-independent gene set was strongly induced by $\triangle \mathrm{SAP}-\mathrm{Mkl1}$ but not by mutB1-Mkl1, as 


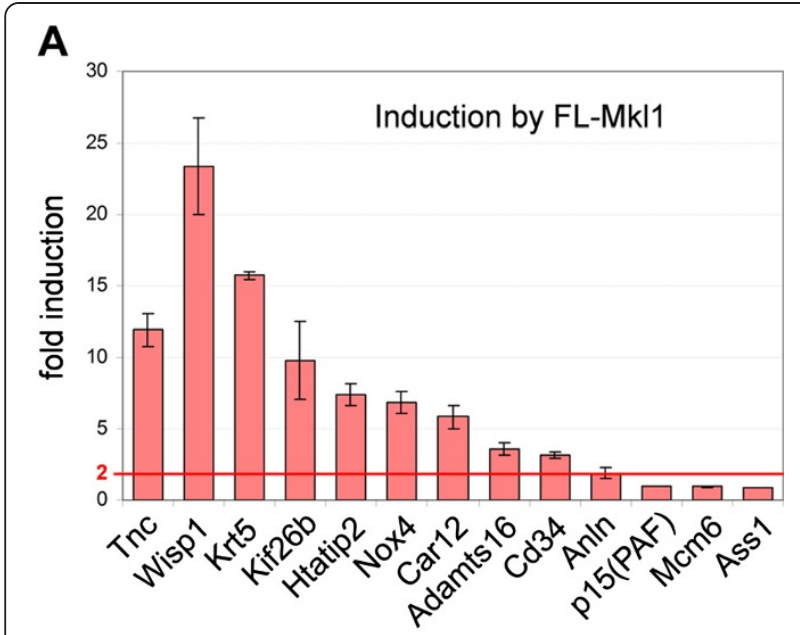

B

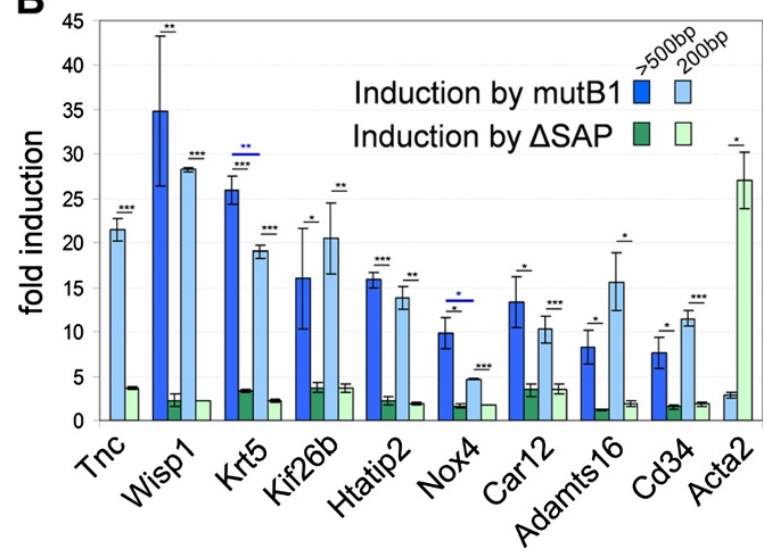

Figure 2 SRF-independent/SAP-dependent transcripts represent direct Mkl1 target genes requiring the SAP domain of Mkl1 to induce transcription from their proximal promoter. (A) The indicated promoter constructs that contained at least $500 \mathrm{bp}$ upstream of the transcription start site (TSS) and were linked to the secreted alkaline phosphatase (SEAP) reporter gene, were cotransfected in $\mathrm{HC} 11$ cells together with an inactive Mkl1 devoid of the transactivation domain [13] or the FL-Mkl1 construct. SEAP activity is expressed as fold induction above the level obtained with the inactive Mkl1. In addition to Tnc, for 8 out of the 12 new promoters tested, induction greater than 2 -fold (indicated by the red line) was obtained. Values are means \pm SEM from three to seven independent experiments. (B) $\mathrm{HC} 11$ cells were cotransfected with the indicated promoter constructs that were either $>500 \mathrm{bp}$ or shortened to $200 \mathrm{bp}$ upstream of the TSS, and with vectors encoding the indicated mutant Mkl1 constructs. SEAP activity is normalized and expressed as in (A). Means \pm SEM from at least three independent experiments and significant differences between either mutB1- and $\triangle$ SAP-Mkl1transactivated promoter constructs or between the longer and shorter promoter constructs transactivated by mutB1-Mkl1, ${ }^{* *} \mathrm{P}<0.001$, ${ }^{* *} \mathrm{P}<0.01,{ }^{*} \mathrm{P}<0.05$ are shown.

expected for a typical SRF/Mkl1 target gene [18,55,56]. All promoters that revealed SAP-dependency were shortened to $200 \mathrm{bp}$ upstream of the TSS to test whether this was sufficient to relay the Mkl1 response, as it has been seen previously for tenascin-C [13]. With the exception of Krt5 and Nox4, for which some activity was lost by shortening the promoters, the $200 \mathrm{bp}$ proximal promoters of all other genes tested were induced equally well as the longer constructs (Figure 2B). Thus, we conclude that there are many genes that are regulated similarly as tenascin- $\mathrm{C}$ requiring the SAP domain of Mkl1 to induce transcription from their proximal promoter.

\section{The different HC11 cell strains proliferate at different rates and show distinct migration behaviors}

Next, we tested whether the differential gene expression seen in the different $\mathrm{HC} 11$ strains overexpressing either FL-, mutB1- or $\triangle$ SAP-Mkl1 constructs have functional consequences on their behavior. Since most of the SAPdependent transcripts are proposed to have a function in cancer, we decided to analyze two main functions important for cancer progression: proliferation and cell migration. An approximately equal overexpression of the different Mkl1 protein variants in the $\mathrm{HC11}$ cell lines was confirmed by Western blot analysis (Figure 3A). An HC11 cell strain stably transfected with an empty vector [13] expressing only endogenous Mkl1 (below the detection limit in Figure 3A) was also included in these studies. The proliferation rates of the HC11 strains were analyzed using a 5-bromo-2'-deoxyuridine (BrdU) incorporation assay. The incorporated BrdU was measured immediately after plating $(0 \mathrm{~h})$ as well as at $24,48,72$ and 96 h. Compared to empty vector-, FL- or mutB1transfected HC11 strains, there was a significant decrease in BrdU uptake into newly synthesized DNA in HC11$\triangle$ SAP cells over the entire time period tested (Figure $3 \mathrm{~B}$ ). To investigate cell motility, we used a transfilter migration assay. Similarly to the effect on cellular proliferation, the expression of $\triangle$ SAP-Mkl1 significantly inhibited HC11 cell migration by 2.7 -fold compared to endogenous or full length Mkl1 expression, and more than 3.5-fold compared to mutB1-Mkl1 expression (Figure 3C).

Thus, overexpression of FL-Mkl1 protein in HC11 cells did not affect their behavior. However, overexpression of $\triangle$ SAP-Mkl1 led to a significant reduction in the proliferative and migratory ability of $\mathrm{HC} 11$ epithelial cells, either through a dominant-negative effect of $\triangle$ SAP-Mkl1 on SRF-mediated action and/or a positive impact of the SAP-dependent Mkl1 target genes on these functions important for cancer progression.

\section{SAP-dependent Mkl1 target genes are mechanoresponsive}

We have previously found that the SAP-dependent induction of tenascin- $C$ was triggered by applying mechanical strain to fibroblasts. Mammary epithelial cells are also exposed to mechanical strains, both during normal development, pregnancy and lactation, as well as under pathological conditions such as in cancer. Therefore, we 

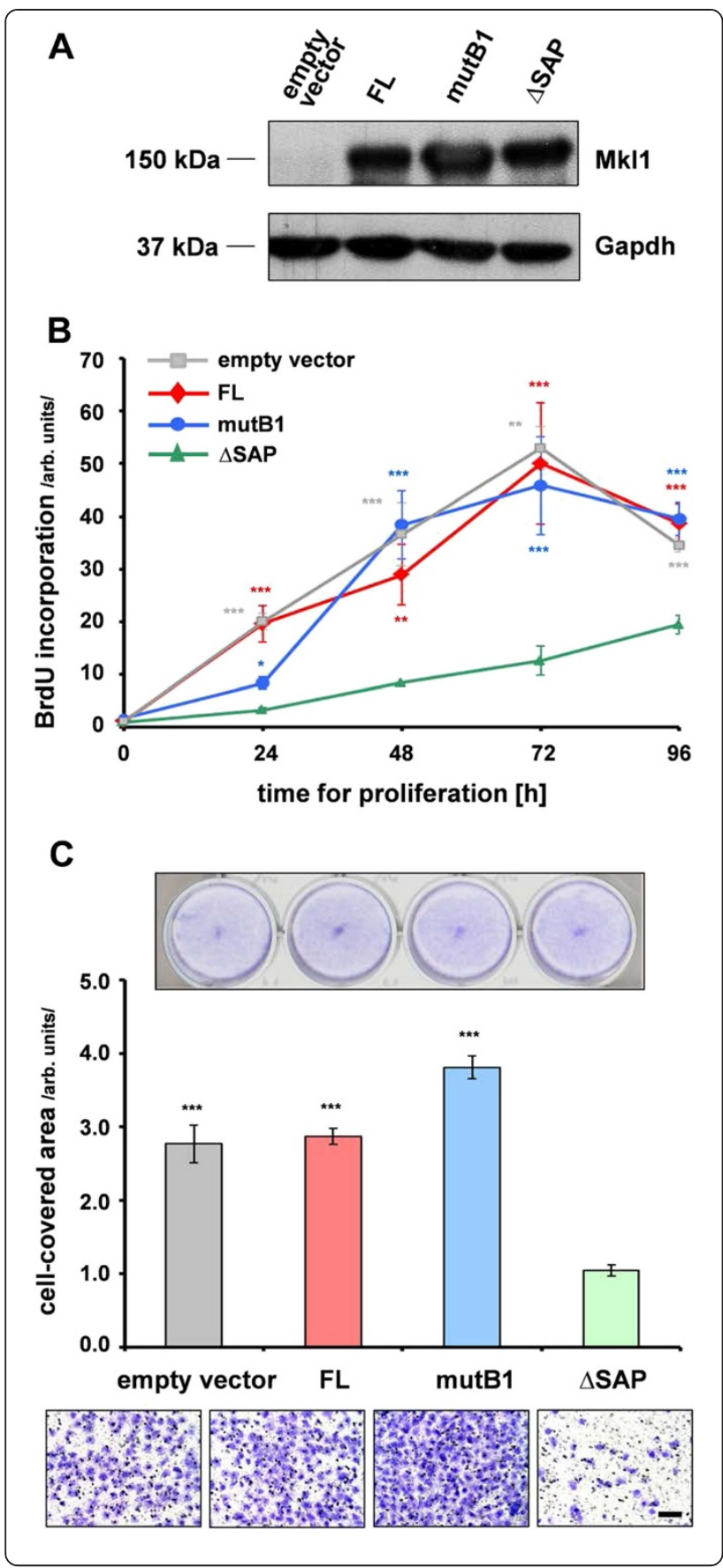

Figure 3 The different $\mathrm{HC} 11$ cell strains proliferate at different rates and show distinct migration behaviors. (A) Immunoblot with $\mathrm{mAb} 65 \mathrm{~F} 13$ of Mkl1 proteins in whole-cell extracts from the empty vector-, FL-, mutB1- or $\triangle \mathrm{SAP}$-transfected HC11 strains. Anti-Gapdh served as loading control. Endogenous Mkl1 protein was below the detection limit in empty vector cells. (B) SAP-dependent proliferation of HC11 mammary epithelial cells. Proliferation rates of the four $\mathrm{HC} 11$ cell strains were assessed by BrdU incorporation into newly synthesized DNA immediately after plating $(0 \mathrm{~h})$ as well as at $24,48,72$ and $96 \mathrm{~h}$. Means \pm SD from three independent experiments and significant differences to the HC11- $\triangle$ SAP cells, ${ }^{*}{ }^{*} \mathrm{P}<0.001$, ${ }^{*} \mathrm{P}<0.01,{ }^{*} \mathrm{P}<0.05$ are shown. (C) SAP-dependent migration of HC11 mammary epithelial cells. Cell migration of the four HC11 strains was evaluated by Transwell migration assay using filters with $8 \mu \mathrm{m}$ pore size. Quantification of the cell migration was measured by the area on the lower side of the filter covered with cells. Above the bar graph, a photo of fixed and stained cells seeded in parallel in a 24-well plate is shown as a seeding control, and representative photos of fixed and stained cells of each of the cell strains that have migrated to the lower side of the filter, are shown below (bar, $200 \mu \mathrm{m})$. Data and statistical significance are expressed as in (B).

tested whether tenascin- $\mathrm{C}$ and other members of the SAP-dependent Mkl1-induced gene set are mechanoresponsive in HC11 cells. We tested two paradigms: 1) static strain that was shown to induce c-fos, a very prominent mechanoresponsive gene in $\mathrm{HC11}$ cells [57] that we used as a control, and 2) cyclic strain. While we were able to confirm induction of c-fos by applying static strain at $20 \%$ for $1 \mathrm{~h}$, there was no induction of tenascin- $\mathrm{C}$ under these conditions compared to cells at rest (Figure 4A). However, using $15 \%$ cyclic strain at a frequency of $0.3 \mathrm{~Hz}$ for $1 \mathrm{~h}$, we found that not only the control gene c-fos but 11 out of 16 SAP-dependent genes, including tenascin- $C$ were significantly upregulated above the expression levels obtained in resting cells (Figure 4). Even though significant, the induction of tenascin-C was minimal (Figure 4A) compared to 18-fold upregulation for Adamts16 or 10-fold upregulation for Lox (Figure 4B), both of which are enzymes involved in extracellular matrix (ECM) remodeling and cancer progression [31,58]. Being mechanoresponsive, the SAP-dependent Mkl1 target genes might be activated in stiff tumor tissue, which further confirms their relation with cancer.

The SRF-independent/SAP-dependent genes represent a bad prognostic signature for breast cancer patients

In order to investigate whether the SRF-independent/SAPdependent genes were prognostic of accelerated cancer progression in human patients, we used the bioinformatics tool Gene expression-based Outcome for Breast cancer Online (GOBO) that allowed us to investigate a breast tumor data set containing 1881 samples analyzed by Affymetrix Human Genome U133A arrays. GOBO is designed to assess gene expression levels and association with outcome of single genes or gene sets in multiple subgroups of 


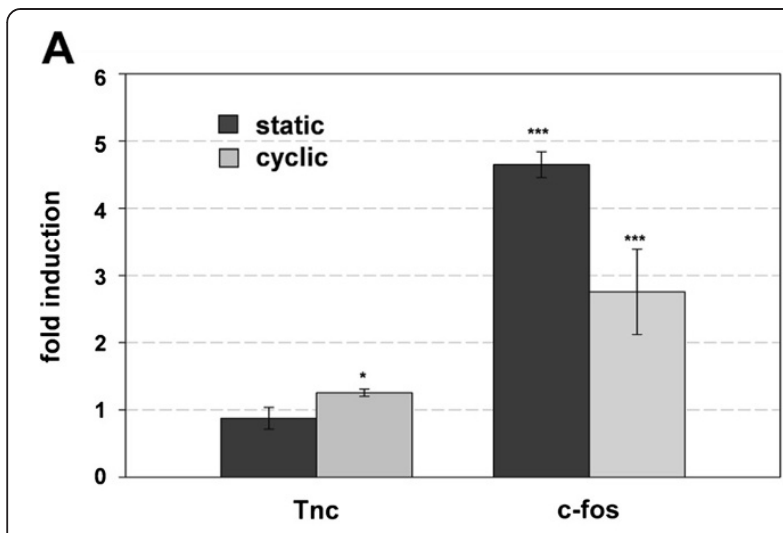

B

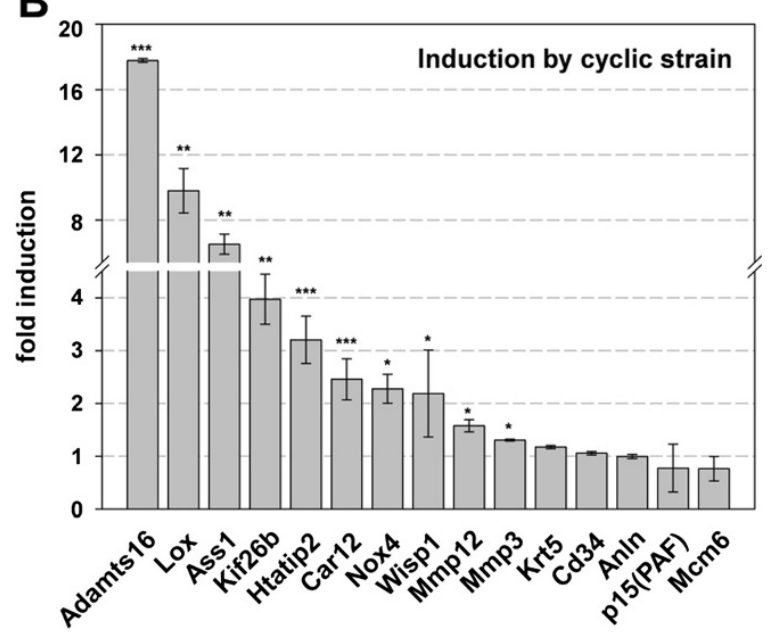

Figure 4 SAP-dependent Mkl1 target genes are mechanoresponsive. (A) Effect of static (20\%) and cyclic (15\%, $0.3 \mathrm{~Hz}$ ) strain on Tnc and c-fos mRNA levels. HC11 cells were cultured on either growth factor reduced matrigel matrix- or fibronectin-coated silicone membranes in $0.03 \%$ serum-containing medium for $24 \mathrm{~h}$ before applying static or cyclic strain for $1 \mathrm{~h}$. Cells cultured under the same conditions and not exposed to mechanical stimulation were used as a resting control. The two types of coating gave identical results under the indicated experimental conditions. Total RNA was extracted and qRT-PCR was performed for Tnc and c-fos mRNA levels. Values normalized to Gapdh are expressed relative to the values of resting cells. Data represent means \pm SD from three independent experiments. Significant differences to the resting control, ${ }^{* *} \mathrm{P}<0.001,{ }^{* * P}<0.01$, ${ }^{* P}<0.05$. (B) SAP-dependent genes respond to cyclic strain. $\mathrm{HC} 11$ cells were stretched and mRNA analyses were performed as described in (A). Data and statistical significance are expressed as in (A).

this breast cancer data set [59]. Here, we analyzed two sets of genes, namely the SRF/Mkl1-induced gene set (SRF-dependent/SAP-independent) and the SAP-dependent gene set (SRF-independent/SAP-dependent) containing tenascin-C. The analysis was performed across tumor samples stratified according to PAM50 subtypes [60], estrogen receptor (ER)-status and histological grade. In contrast to the SRF/Mkl1 target genes that were predominantly associated with tumors classified as normal-like and with lower histological grades (1 and 2) (Figure 5A), elevated expression of SAP-dependent genes was associated with extremely high significance $(\mathrm{P}<0.00001)$ with typical high-proliferative poor outcome classes in breast cancer, such as basal-like, HER2-enriched, luminal B, ERnegative and histological grade 3 tumors (Figure 5B). Next, a functional correlation analysis to find a possible interconnection between the SAP-dependent Mkl1 target genes was performed using the GOBO tool (Additional file 4: Figure S3). This analysis explores the correlation of expression of individual genes in our gene sets with eight different co-expressed gene modules emulating breast cancer-specific as well as general tumor biological processes [61]. Interestingly, whereas the gene set of SRF/ Mkl1 targets did not show a significant correlation with any of these modules, the genes in the SAP-dependent gene set were correlated with a very high significance $(\mathrm{P}<0.00001)$ with two proliferation modules - mitotic checkpoint and mitotic progression. Both modules contain genes related to central mitotic processes involved in either the regulation of the M-phase and the mitotic checkpoint or in carrying out the M-phase. Finally, the association of our gene sets with outcome using distant metastasis free survival (DMFS) as an endpoint and 10year censoring was analyzed. The survival analysis was performed in all tumors for which DMFS follow-up is available (1379 cases), as well as in 21 groups that were stratified based on gene expression subtypes (PAM50 classifier), ER-status, lymph node (LN)-status, histological grade, and treatment status. Samples in the whole cancer data set (1881 patients) were stratified into three quantiles, low, intermediate and high, based on SRF-dependent/ SAP-independent or SRF-independent/SAP-dependent gene expression. Interestingly, high expression of SRF/Mkl1induced genes was associated with a better clinical outcome for all tumors, as well as for LN-negative and untreated tumors compared to low and intermediate expression of these genes (Figure 6A). In contrast, both high and intermediate expression of the SAP-dependent genes was associated with bad clinical outcome in all tumors, and particularly in LN-negative, systemically untreated, ER-positive, Grade 1 and 2 tumors (Figure 6B). Similar results were obtained for the typical breast cancer gene CCNB1 by Ringnér et al. [59]. The Kaplan-Meier survival analyses were supported by the corresponding multivariate analyses (Figure 7A, B). The hazard ratio for the variate Grade shows statistical significance, proving that the influence of high SAP-dependent gene expression on patient survival is independent of tumor grade. Among all tumors for which DMFS data are available, a hazard ratio of 0.44 (95\% $\mathrm{CI}=0.28-0.68 ; \mathrm{P}=0.0003$ ) for the low SRF-independent/SAP-dependent tercile was detected compared to the high SRF-independent/SAP-dependent tercile (Figure 7B, all tumors). This indicates that patients 

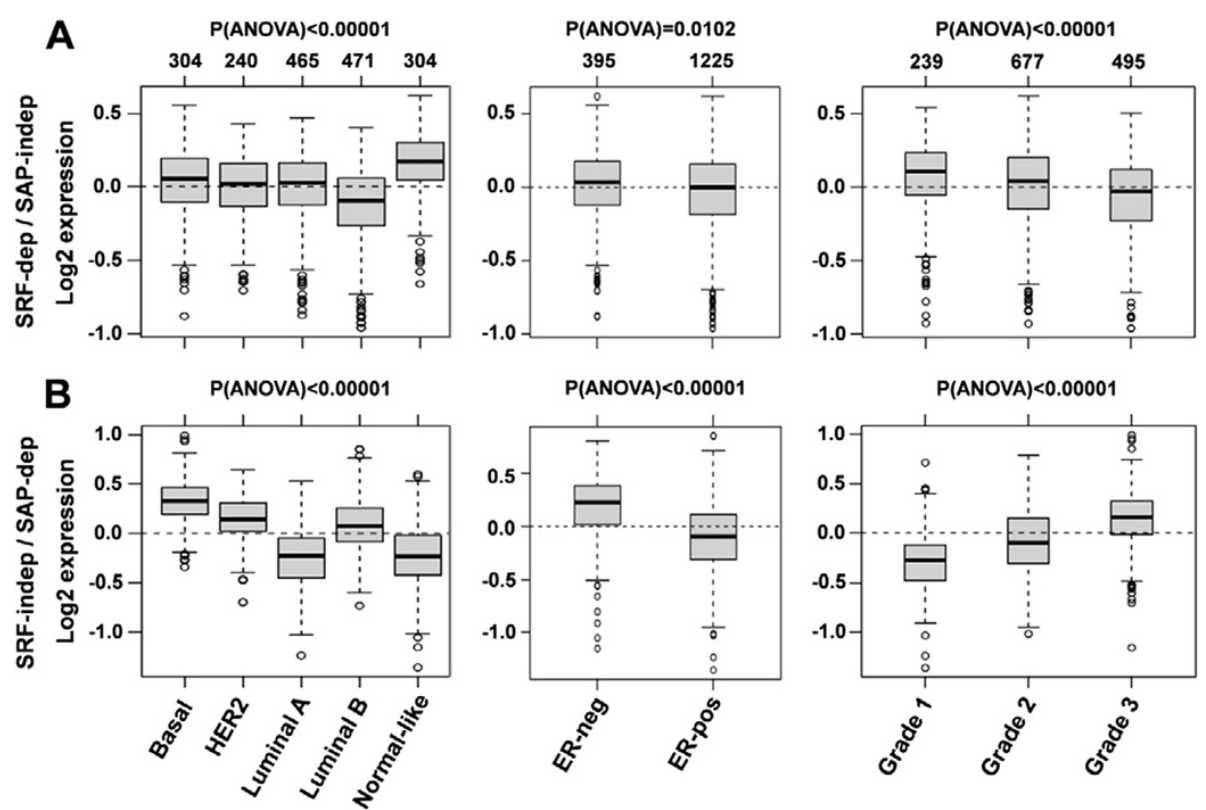

Figure 5 SAP-dependent Mkl1 target genes are associated with typical high-proliferative poor outcome classes in breast cancer. The expression levels for the SRF-dependent/SAP-independent (A) and SRF-independent/SAP-dependent (B) gene sets are analyzed across the 1881-sample breast cancer data set stratified according to PAM50 subtypes (left panels), estrogen receptor (ER)-status (middle panels) and histological grade (right panels), and represented by box plots using the GOBO bioinformatics tool. The number of tumors in each breast cancer subtype and the significant difference in gene expression (P-value calculated using ANOVA) between them are shown above the box plots.

with tumors expressing high levels of the SAP-dependent genes are more than twice as likely to develop metastatic disease. Similar hazard ratios, in the range of 0.28-0.44 for the low tercile compared to the high tercile were also detected among subgroups of untreated, LN-negative, ER-positive, Grade 1 and 2 tumors (Figure 7B). Thus, the association of high SRF-independent/SAP-dependent gene expression with reduced DMFS among patients not receiving adjuvant therapy, as well as among LN-negative, ER-positive, Grade 1 and 2 patients indicates that increased expression of the SAP-dependent Mkl1 target genes plays a significant role in the natural metastatic progression of non-aggressive towards highly aggressive breast cancer in human patients.

\section{Discussion}

Given the heterogeneity of mutations in tumor cells, it becomes increasingly clear that not only individual genes but pathways govern the course of tumorigenesis and cancer progression [62]. We have recently shown that induction of tenascin-C by cyclic mechanical strain required the action of the potential DNA-binding SAP domain of Mkl1 independently of an interaction of Mkl1 with SRF [13]. Now, we report a screen for genes co-regulated with tenascin- $\mathrm{C}$ by the same SAP-dependent and SRF-independent mechanism in mammary epithelial cells. This screen reveals a set of SAP domain-dependent
Mkl1 target genes with a strong implication in cell proliferation, cell motility and cancer.

To date only a few studies have shown that Mkl1 is implicated in cancer-related processes (reviewed in [63]) and most of them have concentrated on the SRF/Mkl1 signaling for the induction of individual genes [64-67]. The first study reporting that depletion of Mkl1/2 proteins reduced motility, invasion and colonization of metastatic tumor cells in an experimental in vivo metastasis assay [64] was further supported by the discovery of the Mkl1binding protein, suppressor of cancer cell invasion (SCAI), which inhibited SRF/Mkl1-mediated expression of $\beta 1$ integrin [68]. Since then, several studies describing opposing biological effects for Mkl1 appeared. For instance, several antiproliferative SRF/Mkl1 target genes including mig6/ errfi-1, a negative regulator of the EGFR-MAPK pathway, were identified [65], or the tumor suppressor gene Eplin- $\alpha$ was described as a direct target of the SRF/Mkl1 pathway [66]. Furthermore, expression of a constitutively active form of Mkl1 in oncogenic ras- or src-transformed rat intestinal epithelial cells injected into the spleen of nude mice significantly suppressed tumor formation and reduced liver metastases by rescuing the expression of the SRF/Mkl1 targets tropomyosin and caldesmon [67]. In line with these findings, we could show that high expression of SRF/Mkl1 target genes is associated with an improved clinical outcome in breast cancer patients. However, the opposite is the case for high expression 


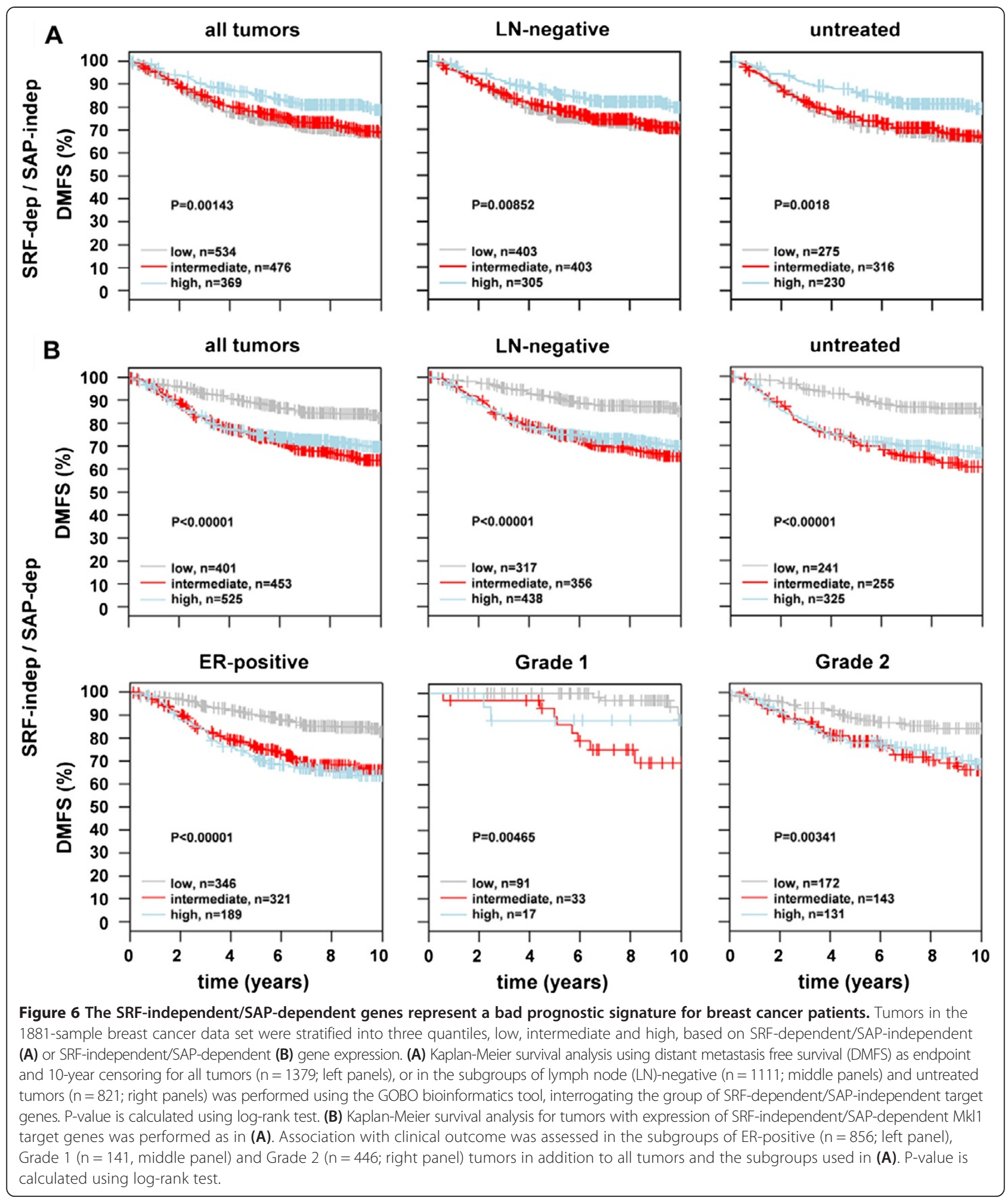

of SAP-dependent Mkl1 target genes. These genes are associated with poor clinical outcome predominantly in less aggressive tumors such as LN-negative, ER-positive, Grade 1 and 2 tumors, which makes them valuable predictors of breast cancer progression. A scheme that depicts our model for Mkl1 action in breast cancer is presented in Figure 8. In this model Mkl1 is transactivating SRF-target genes in less aggressive tumors, while in the course of cancer progression and metastatic behavior Mkl1 is activating a new group of genes in a SAP-dependent manner either by direct 

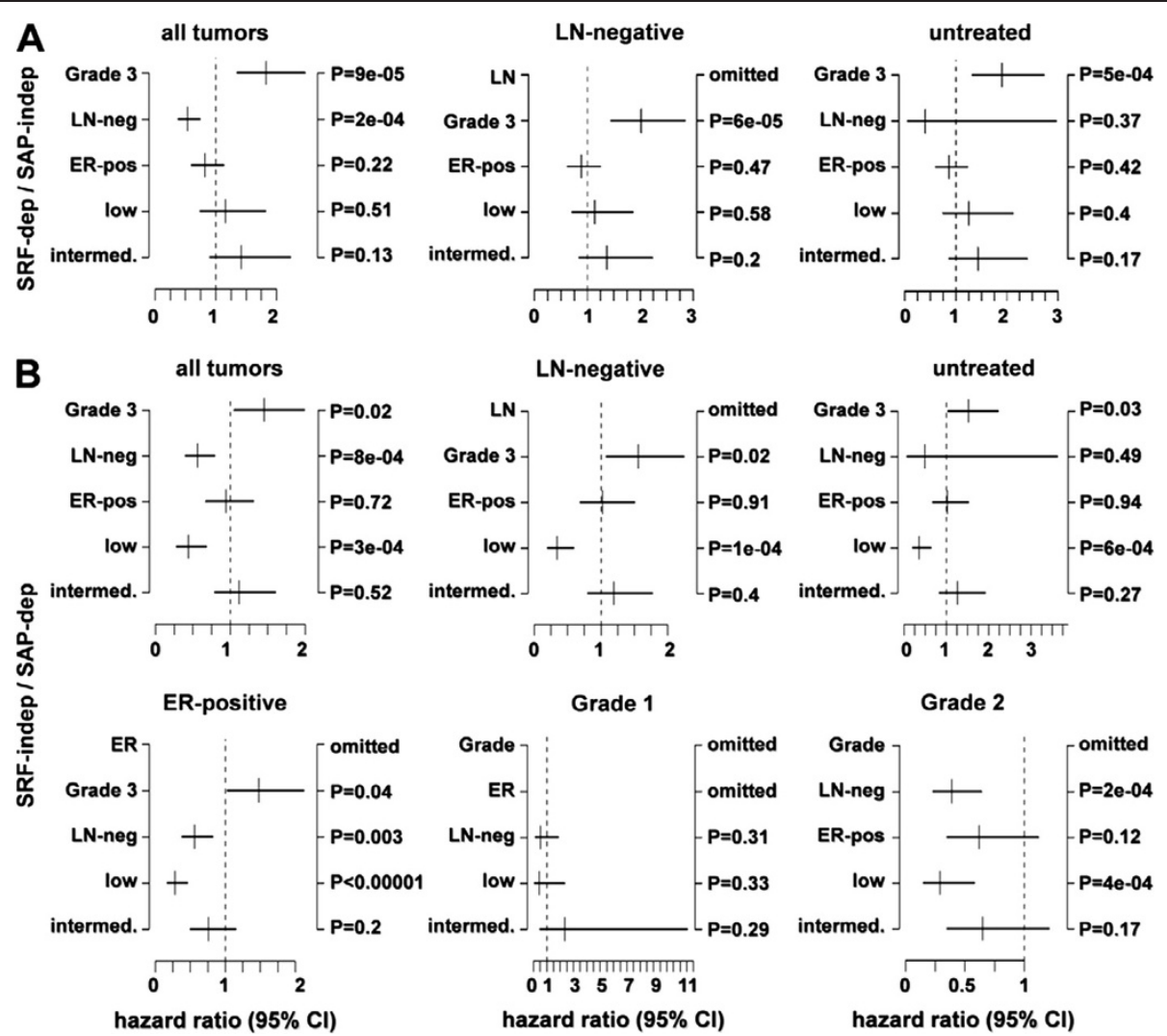

Figure 7 Elevated expression of SAP-dependent Mkl1 target genes is a poor prognosis factor in breast cancer independent of histological grade. Multivariate analysis supporting the Kaplan-Maier survival analysis (shown in Figure 6) for the SRF-dependent/SAP-independent (A) and SRF-independent/SAP-dependent (B) gene sets, was performed using the GOBO bioinformatics tool. The analysis was executed for all tumors $(n=1379)$ and in the subgroups of $L N$-negative $(n=1111)$ and untreated tumors $(n=821)(\mathbf{A}, \mathbf{B})$, as well as in the subgroups of ER-positive ( $n=856)$, Grade $1(n=141)$ and Grade $2(n=446)$ tumors $(B)$, using LN-status, ER-status, and stratified histological grade (histological grade 1 and 2 vs. 3) as covariates, DMFS as endpoint and 10-year censoring. The hazard ratio and the $95 \%$ confidence interval (Cl) are plotted for each of these covariates. Specified covariates may be omitted in certain comparisons, e.g. ER-status is omitted when analyzing ER-positive tumors only, or when not all of the investigated cases have clinical follow-up or clinical information for the specified covariate.

interaction with the promoters of these genes or by interaction with additional DNA-binding factors.

Interestingly, in parental $\mathrm{HC} 11$ cells many of the genes that we found in the SAP-dependent gene set that foster cell proliferation and migration and may cause poor survival of breast cancer patients are also induced by mechanical strain. A recent study has demonstrated that inhibition of cell spreading due to a lack of matrix stiffness is overcome by externally applied stretch, suggesting that similar mechanotransduction mechanisms sense stiffness and stretch [69]. Tumor stroma is typically stiffer than normal stroma. In breast cancer, diseased tissue can be 10 times stiffer than normal breast [70,71]. It is known that abnormal ECM stiffness plays an important role in cancer progression [72,73], but the mechanisms by which stiffness influences cancer progression are still under investigation. If we assume that we have discovered a general reaction of mammary epithelial cells to mechanical strain, we envisage that epithelial cells in a stiff, mechanically dynamic tumor environment may react by inducing a SAP-dependent Mkl1 gene set that in turn affects tumor progression. Furthermore, the products of these genes, many of which are involved in ECM turnover and function, for example Lox [58], Mmps [74], Adamts16 [31] or Wisp1 [44] might themselves manipulate the tumor microenvironment, thereby influencing tumor cell survival by a positive tumorigenic feedback loop.

Finding how to switch the mode of action of Mkl1 between SRF transactivation versus its SAP-dependent transcriptional activity is a subject of ongoing research in our lab that in future may help with the development of new therapeutic interventions for breast cancer. Posttranslational modifications such as sumoylation are known to influence Mkl1 transcriptional activity [75] and phosphorylation has been shown to influence interaction of Mkl1 with nuclear actin resulting in transcriptional changes [76,77]. Further characterization of these and 


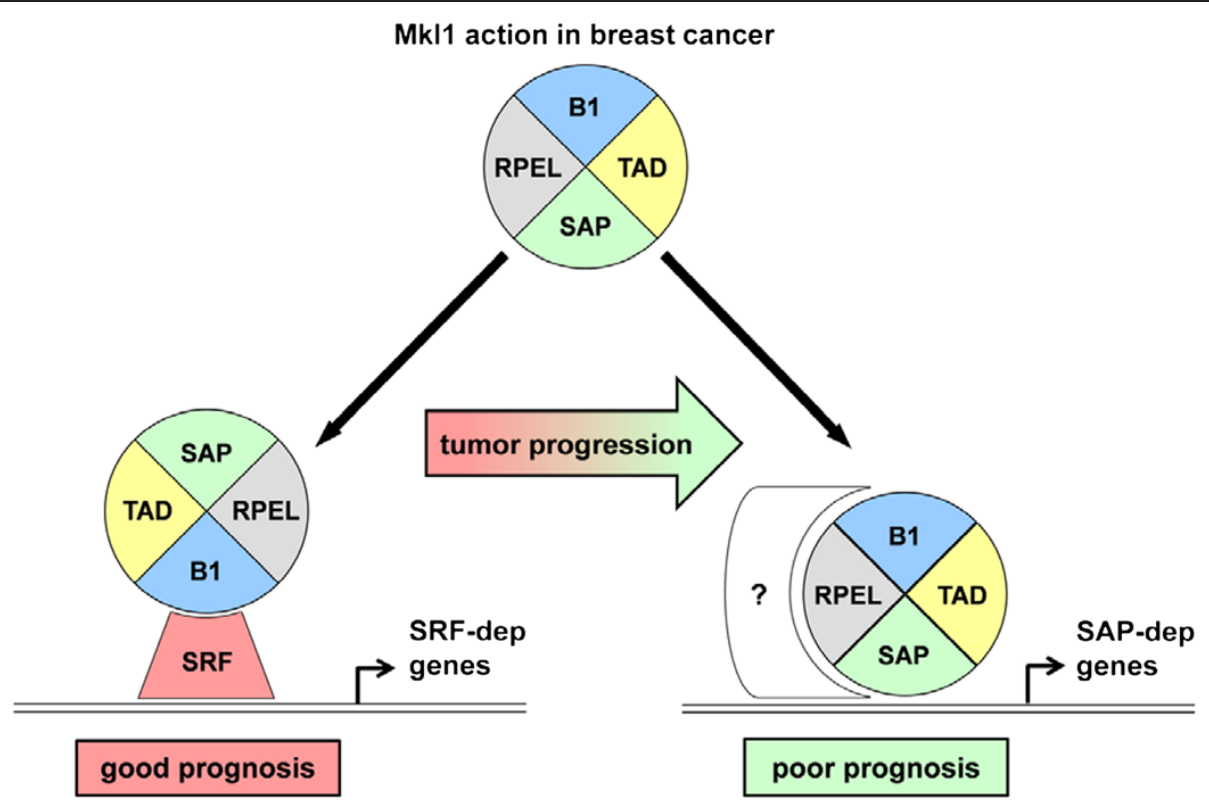

Figure 8 Schematic representation of the Mkl1 action in breast cancer. A circular Mkl1 model is depicted with four of its domains: RPEL, actin binding motifs with RPxxxEL core consensus; B1, basic domain involved in SRF-binding; SAP, homology domain found in the nuclear proteins SAF-A/B, Acinus, PIAS; TAD, transactivation domain. Serum response factor is drawn as a red shape and putative unidentified DNA-binding proteins as white shape with a question mark. Mkl1 exerts two distinct modes of action: one of them is through the B1 domain required for serum response factor (SRF)-binding activity and induction of SRF/Mkl1 target gene expression; the other one is strongly dependent on the SAP domain and triggers the expression of a specific set of pro-proliferative and pro-migratory genes that we called SAP-dependent Mkl1 target genes. High expression of SRF-dependent genes is associated with good clinical outcome for breast cancer patients, whereas elevated expression of SAP-dependent targets correlates with poor prognosis and indicates a significant role for these genes in breast cancer progression.

other post-transcriptional changes of Mkl1 deserve special attention when trying to answer the above question.

\section{Conclusions}

In the current study, we discovered a breast cancerspecific set of genes that is highly interesting as a prognostic marker and therapeutic target for several reasons. (1) The expression of this gene set is regulated by Mkl1 and its SAP domain and is independent of SRF. (2) The SAP-dependent, SRF-independent Mkl1signaling is triggered by mechanical strain and may thus be activated in stiff tumors with a high stromal content and high interstitial tissue pressure. (3) This gene set is composed of interesting members some of which represent novel candidates for playing a functional role in cancer and others that have already been implicated in cancerrelated functions, as for example tenascin- $\mathrm{C}$, a metastatic niche component important for lung colonization [8], or Lox as a gene mediating collagen crosslinking responsible for fibrosis-enhanced metastasis [58]. (4) The SAP-dependent Mkl1 target genes are associated with a poor clinical outcome in breast cancer patients, not receiving adjuvant therapy or having a cancer classified as non-aggressive such as LN-negative, ER-positive, Grade 1 or 2 tumors. This makes these genes potential valuable prognostic markers in selecting patients who may benefit from an immediate and/or more aggressive therapy.

\section{Methods}

Cell culture

Full length Mkl1 (FL-Mkl1) and the two Mkl1 mutants, mutB1-Mkl1 comprising alanine substitutions of four amino acids (underlined) in the B1 domain of Mkl1 (KKA KELKPKVKKLKYHQYIPPDQKQD) [78] and $\triangle$ SAP-Mkl1 with a deletion of the SAP domain [15], were constructed based on transcript variant 1 (GenBank accession number NM_153049) as previously described [13]. All Mkl1 variants were expressed as C-terminal RFP-tagged fusions. An empty vector expressing RFP alone was previously described [13].

HC11 mammary epithelial cells, kindly provided by Dr. N. Hynes (Basel, Switzerland), were grown in RPMI1640 medium supplemented with $10 \%$ FCS, $5 \mu \mathrm{g} / \mathrm{ml}$ insulin (Sigma, Buchs, Switzerland) and $10 \mathrm{ng} / \mathrm{ml}$ epidermal growth factor (EGF; Invitrogen, Zug, Switzerland). In most of the experiments, the HC11 cells were starved in $0.03 \%$ FCS/RPMI without EGF. To obtain HC11 cells stably expressing FL-Mkl1-RFP (HC11-FL), mutB1-Mkl1-RFP (HC11-mutB1), $\triangle$ SAP-Mkl1-RFP (HC11- $\triangle \mathrm{SAP}$ ) or RFP alone (HC11-empty vector), cells were transfected using FuGENE 6 (Roche, Basel, Switzerland) and selected 
with Geneticin (1 mg/ml; Roche) for 14 days before fluorescence-activated cell sorting (FACS) of RFP-positive cells on a Vantage SE (Becton Dickinson, Basel, Switzerland). Cell viability of the four HC11 cell strains was assessed by the CellTiter-Blue viability assay (Promega, Duebendorf, Switzerland).

\section{Cell proliferation assay}

Proliferation rates of the $\mathrm{HC} 11$ cell strains were determined using BrdU incorporation assay (Roche). After $24 \mathrm{~h}$ of starvation, cells were plated in triplicate on Black 96-well microtiter plates (PerkinElmer, Schwerzenbach, Switzerland) at $5 \times 10^{3}$ cells/well in 3\% FCS/RPMI and allowed to proliferate for 0, 24, 48, 72 and $96 \mathrm{~h}$ before labeling with BrdU for $2 \mathrm{~h}$. BrdU incorporation into newly synthesized DNA was determined according to the manufacturer's protocol using a Luminometer Mithras LB940 (Berthold Technologies, Regensdorf, Switzerland). Experimental values were normalized to the values of HC11- $\triangle$ SAP cells at the time point 0 . Data represent means \pm SD from three independent experiments.

\section{Cell migration assay}

Cell migration was assayed using transwell polycarbonate membrane inserts $(6.5 \mathrm{~mm}$; Corning, Amsterdam, The Netherlands) with $8 \mu \mathrm{m}$ pores as described [79]. After $24 \mathrm{~h}$ of starvation, $5 \times 10^{4}$ cells were plated in the top insert chamber with $100 \mu \mathrm{l}$ serum-free RPMI. The lower chamber was filled with $600 \mu \mathrm{l} 10 \% \mathrm{FCS} / \mathrm{RPMI}$. Cells were allowed to migrate across the filter for $22 \mathrm{~h}$ at $37^{\circ} \mathrm{C}$ before fixation and crystal violet-staining. Images of duplicate inserts were acquired on a Nikon Eclipse E600 using 10x magnification and a color CCD camera. Migration was quantified by measuring the area covered by migrated cells using the Fiji distribution of ImageJ [80]. Data represent means \pm SD from three independent experiments.

\section{Mechanical stimulation of cells}

$2 \times 10^{5} \mathrm{HC} 11$ cells/well were seeded in BioFlex ${ }^{\oplus}$ 6-well culture plates (Flexcell International, Hillsborough, NC, USA) coated with either growth factor reduced-Matrigel (BD Biosciences, Basel, Switzerland) or fibronectin [11]. Cultures were starved for $24 \mathrm{~h}$ before applying either equibiaxial cyclic strain $(15 \%, 0.3 \mathrm{~Hz})$ or static strain (20\%) at $37^{\circ} \mathrm{C}$ for $1 \mathrm{~h}$ using Flexcell FX-4000 (Flexcell International). Cells cultured under the same conditions and not exposed to strain were used as a resting control. After mechanical stimulation, cells were lysed and total RNA was isolated using the RNeasy Mini Kit (Qiagen, Basel, Switzerland).

\section{Transcript profiling and bioinformatics analysis}

HC11 cell strains stably expressing Mkl1 variants were starved for $48 \mathrm{~h}$ before total RNA was extracted, converted into labeled cDNA and hybridized to Affymetrix GeneChip Mouse Gene 1.0 ST arrays. RMAnormalized expression values were calculated with the Affy package from Bioconductor 2.4 [81], and differentially expressed genes were identified using moderated $t$-statistics calculated with the empirical Bayes method as implemented in the Bioconductor limma package [82]. To be considered as differentially expressed between HC11-FL and HC11-mutB1 or HC11- $\triangle$ SAP cells, genes had to pass the filters: adjusted P-value $\leq$ 0.01 (with Benjamin-Hochberg false discovery correction), a minimum absolute linear fold change difference of 2.0 and a minimum average expression value of $4.0(\log 2)$. Microarray data files are available from the Gene Expression Omnibus (GEO; http://www.ncbi.nlm. nih.gov/geo/), accession number GSE44907. Using the above parameters, gene lists of the two contrasts (mutB1/ $\mathrm{FL}$ and $\triangle \mathrm{SAP} / \mathrm{FL}$ ) were compared resulting in the formation of three gene groups: SRF-dependent/SAP-independent, SRF-dependent/SAP-dependent and SRF-independent/ SAP-dependent. The three gene sets were analyzed using the bioinformatics softwares: 1) IPA (Ingenuity ${ }^{\circ}$ Systems; www.ingenuity.com); and 2) GOBO (http://co.bmc.lu.se/ gobo) [59]. In order to use the latter tool, Affymetrix GeneChip Mouse Gene 1.0 ST IDs were mapped to Affymetrix Human Genome U133A IDs using Biomart for Ensembl build 66. The module "Gene Set Analysis Tumors" was used to investigate the expression pattern and to perform survival and functional correlation analyses for the SRF-dependent/SAP-independent and SRF-independent/ SAP-dependent gene sets across 1881 breast cancers characterized by Affymetrix Human Genome U133A arrays.

\section{RNA analyses by qRT-PCR}

Total RNA was isolated from HC11 cell strains after $24 \mathrm{~h}$ of incubation either in 0.03 or $3 \%$ FCS/RPMI. RNA was reverse transcribed and relative tenascin-C and c-fos mRNA levels were detected as described $[12,13]$. Relative mRNA levels for the genes listed in Table 1, normalized to Gapdh, were measured using Platinum $^{\oplus}$ SYBR $^{\odot}$ Green qPCR SuperMix-UDG with ROX (Invitrogen) and the primers listed in Additional file 4: Table S4. Real-time PCR was performed in a StepOnePlus Real-Time PCR System (Applied Biosystems, Rotkreuz, Switzerland) using a standard cycling profile. All samples were run in duplicate. Data were analyzed by the $\Delta C$ t method [83] and presented as fold changes in mRNA expression levels between HC11-FL and HC11- $\triangle$ SAP cells. RNA from stretched cells was analyzed by qRT-PCR using the efficiency $\Delta \Delta \mathrm{Ct}$ method [84] that included a further normalization to the resting control. Data represent means \pm SD from three independent experiments. 
Protein analyses by immunoblotting and zymography After $24 \mathrm{~h}$ of starvation, whole-cell extracts from the three HC11 strains were prepared in RIPA buffer and immunoblotting was performed as described [12,13]. The following primary antibodies were used: mAb65F13 anti-Mkl1 [12], MTn12 anti-Tnc [85], anti-Wisp1/CCN4 (clone 214203, R\&D Systems), anti-Nox4 (NB110-58851, Novus Biologicals), anti-Vcl (clone hVIN-1, Sigma) and anti-Gapdh (ab9485, Abcam).

After reaching 90\% confluency, HC11 strains were starved for $48 \mathrm{~h}$ before conditioned medium was collected, concentrated and analyzed by zymography as described [86].

\section{Promoter-reporter assays}

The tenascin- $\mathrm{C}$ promoter used in this study was described as TNC 247 bp [13]. Promoters of Acta2 [87] and all SRFindependent/SAP-dependent genes described in Table 1 were PCR-amplified from genomic DNA and corresponded to the sequences listed in Additional file 4: Table S5. Each promoter contained $\geq 500 \mathrm{bp} 5^{\prime}$ of the TSS and was cloned into the pSEAP2-Basic (Clontech, Saint-Germain-en-Laye, France). For some promoters also 200 bp proximal promoter sequences were cloned as described above. All clones were verified by DNA sequencing.

HC11 cells in 6-well plates were cotransfected with $1 \mu \mathrm{g}$ of the SEAP reporter vectors, $1 \mu \mathrm{g}$ of pcDNA3 vectors encoding Mkl1 variants [13], and $200 \mathrm{ng}$ of the secreted luciferase MetLuc vector (Clontech) used to normalize for transfection efficiency. Cells were cultured in $0.03 \%$ FCS/RPMI for $24 \mathrm{~h}$ before enzymatic activity measurements were performed as described [13]. Experimental values represent averages of three independent experiments, each performed in duplicate.

\section{Statistical analysis}

Numerical results were expressed as means \pm SD. Statistical analysis was completed using GraphPad InStat Software, version 3.05. The two-tailed Student's $t$ test was used to evaluate differences between two groups. Multiple comparisons were performed using one-way analysis of variance (ANOVA). Values of P less than 0.05 were considered statistically significant. Statistics for bioinformatics analyses is given in figure legends.

\section{Additional files}

Additional file 1: Table S1. SRF-dependent/SAP-independent probeset list.

Additional file 2: Table S2. SRF-dependent/SAP-dependent probeset list.

Additional file 3: Table S3. SRF-independent/SAP-dependent probeset list.
Additional file 4: Table S4. Primer sequences. Table S5. Promoter constructs. Figure S1. Quantification of SAP-dependent Mkl1 target gene expression using qRT-PCR analysis. Figure S2. Differential expression of newly discovered Mkl1 target genes in $\mathrm{HC}_{1} 1$ strains overexpressing either FL-, mutB1- or $\triangle$ SAP-Mkl1 constructs (protein analyses performed by immunoblotting and zymography). Figure S3. SAP-dependent Mkl1 target genes are correlated with a very high significance $(P<0.00001)$ with the two proliferation modules - mitotic checkpoint and mitotic progression (a functional correlation analysis performed using the GOBO bioinformatics tool).

\section{Competing interests}

The authors declare that they have no competing interests.

\section{Authors' contributions}

MBA and RCE conceived the project. MBA designed the experiments. MBA and TR performed transcript profiling of HC11 cell strains and bioinformatics analysis. Promoter-reporter studies were designed by RCE and performed by JF. IG and JF performed Western blot and zymographic analysis, and mechanical strain experiments. IG performed qRT-PCR experiments, cell proliferation and cell migration assays. MBA and RCE interpreted the data and wrote the paper. All authors discussed the results, read and approved the final manuscript.

\section{Acknowledgements}

We thank Hubertus Kohler for FACS service, Stephane Thiry for microarray hybridization, and Matthias Chiquet and Richard P. Tucker for critical reading of the manuscript. This work was supported by grants from the Cancer League of Basel, the Swiss Cancer League and the Swiss National Science Foundation 3100A0-120235 and 31003A_135584 to R.C.E.

Received: 28 June 2013 Accepted: 30 January 2014

Published: 5 February 2014

\section{References}

1. Orend G, Chiquet-Ehrismann R: Tenascin-C induced signaling in cancer. Cancer Lett 2006, 244:143-163.

2. Brellier F, Chiquet-Ehrismann R: How do tenascins influence the birth and life of a malignant cell? J Cell Mol Med 2012, 16:32-40.

3. Jahkola T, Toivonen T, Virtanen I, von Smitten $\mathrm{K}$, Nordling $\mathrm{S}$, von Boguslawski K, Haglund C, Nevanlinna H, Blomqvist C: Tenascin-C expression in invasion border of early breast cancer: a predictor of local and distant recurrence. $\mathrm{Br} J$ Cancer 1998, 78:1507-1513.

4. Tsunoda T, Inada H, Kalembeyi I, Imanaka-Yoshida K, Sakakibara M, Okada R, Katsuta K, Sakakura T, Majima Y, Yoshida T: Involvement of large tenascin-C splice variants in breast cancer progression. Am J Pathol 2003, 162:1857-1867.

5. Minn AJ, Gupta GP, Siegel PM, Bos PD, Shu W, Giri DD, Viale A, Olshen AB, Gerald WL, Massague J: Genes that mediate breast cancer metastasis to lung. Nature 2005, 436:518-524.

6. Calvo A, Catena R, Noble MS, Carbott D, Gil-Bazo I, Gonzalez-Moreno O, Huh J, Sharp R, Qiu TH, Anver MR, et al: Identification of VEGF-regulated genes associated with increased lung metastatic potential: functional involvement of tenascin- $\mathrm{C}$ in tumor growth and lung metastasis. Oncogene 2008, 27:5373-5384.

7. Tavazoie SF, Alarcon C, Oskarsson T, Padua D, Wang Q, Bos PD, Gerald WL, Massague J: Endogenous human microRNAs that suppress breast cancer metastasis. Nature 2008, 451:147-152.

8. Oskarsson T, Acharyya S, Zhang XHF, Vanharanta S, Tavazoie SF, Morris PG, Downey RJ, Manova-Todorova K, Brogi E, Massague J: Breast cancer cells produce tenascin $C$ as a metastatic niche component to colonize the lungs. Nat Med 2011, 17:867-874.

9. O'Connell JT, Sugimoto H, Cooke VG, MacDonald BA, Mehta Al, LeBleu VS, Dewar R, Rocha RM, Brentani RR, Resnick MB, et al: VEGF-A and Tenascin-C produced by S100A4+ stromal cells are important for metastatic colonization. Proc Natl Acad Sci USA 2011, 108:16002-16007.

10. Chiquet-Ehrismann R, Tucker RP: Tenascins and the importance of adhesion modulation. Cold Spring Harb Perspect Bio/ 2011. doi:10.1101/cshperspect. a004960. 
11. Chiquet M, Sarasa-Renedo A, Tunc-Civelek V: Induction of tenascin-C by cyclic tensile strain versus growth factors: distinct contributions by Rho/ ROCK and MAPK signaling pathways. Biochim Biophys Acta 2004 1693:193-204.

12. Maier S, Lutz R, Gelman L, Sarasa-Renedo A, Schenk S, Grashoff C, Chiquet $M$ : Tenascin- $C$ induction by cyclic strain requires integrin-linked kinase. Biochim Biophys Acta 2008, 1783:1150-1162.

13. Asparuhova MB, Ferralli J, Chiquet M, Chiquet-Ehrismann R: The transcriptional regulator megakaryoblastic leukemia-1 mediates serum response factor-independent activation of tenascin- $C$ transcription by mechanical stress. FASEB J 2011, 25:3477-3488

14. Wang DZ, Li S, Hockemeyer D, Sutherland L, Wang Z, Schratt G, Richardson JA, Nordheim A, Olson EN: Potentiation of serum response factor activity by a family of myocardin-related transcription factors. Proc Natl Acad SCi USA 2002, 99:14855-14860.

15. Cen B, Selvaraj A, Burgess RC, Hitzler JK, Ma Z, Morris SW, Prywes R: Megakaryoblastic leukemia 1, a potent transcriptional coactivator for serum response factor (SRF), is required for serum induction of SRF target genes. Mol Cell Biol 2003, 23:6597-6608

16. Miralles F, Posern G, Zaromytidou Al, Treisman R: Actin dynamics control SRF activity by regulation of its coactivator MAL. Cell 2003, 113:329-342.

17. Olson EN, Nordheim A: Linking actin dynamics and gene transcription to drive cellular motile functions. Nat Rev Mol Cell Biol 2010, 11:353-365.

18. Miano JM, Long X, Fujiwara K: Serum response factor: master regulator of the actin cytoskeleton and contractile apparatus. Am J Physiol Cell Physiol 2007, 292:C70-C81.

19. Ball R, Friis R, Schoenenberger C, Doppler W, Groner B: Prolactin regulation of beta-casein gene expression and of a cytosolic 120-kd protein in a cloned mouse mammary epithelial cell line. EMBO J 1988, 7:2089-2095.

20. Humphreys R, Rosen J: Stably transfected HC11 cells provide an in vitro and in vivo model system for studying Wnt gene function. Cell Growth Differ 1997, 8:839-849.

21. Cicalese A, Bonizzi G, Pasi CE, Faretta M, Ronzoni S, Giulini B, Brisken C, Minucci S, Di Fiore PP, Pelicci PG: The tumor suppressor p53 regulates polarity of self-renewing divisions in mammary stem cells. Cell 2009, 138:1083-1095.

22. Williams C, Helguero L, Edvardsson K, Haldosen LA, Gustafsson JA: Gene expression in murine mammary epithelial stem cell-like cells shows similarities to human breast cancer gene expression. Breast Cancer Res 2009, 11:R26.

23. Cen B, Selvaraj A, Prywes R: Myocardin/MKL family of SRF coactivators: key regulators of immediate early and muscle specific gene expression. J Cell Biochem 2004, 93:74-82.

24. Wang DZ, Olson EN: Control of smooth muscle development by the myocardin family of transcriptional coactivators. Curr Opin Genet Dev 2004, 14:558-566.

25. Pipes GCT, Creemers EE, Olson EN: The myocardin family of transcriptional coactivators: versatile regulators of cell growth, migration, and myogenesis. Genes Dev 2006, 20:1545-1556.

26. Piekny AJ, Maddox AS: The myriad roles of Anillin during cytokinesis Semin Cell Dev Biol 2010, 21:881-891.

27. Hall PA, Todd CB, Hyland PL, McDade SS, Grabsch H, Dattani M, et al: The septin-binding protein anillin is overexpressed in diverse human tumors. Clin Cancer Res 2005, 11:6780-6786.

28. Suzuki C, Daigo Y, Ishikawa N, Kato T, Hayama S, Ito T, et al: ANLN plays a critical role in human lung carcinogenesis through the activation of RhoA and by involvement in the phosphoinositide 3-kinase/AKT pathway. Cancer Res 2005, 65:11314-11325.

29. Reddy MM, Fernandes MS, Salgia R, Levine RL, Griffin JD, Sattler M: NADPH oxidases regulate cell growth and migration in myeloid cells transformed by oncogenic tyrosine kinases. Leukemia 2011, 25:281-289.

30. Ushio-Fukai M, Nakamura $Y$ : Reactive oxygen species and angiogenesis: NADPH oxidase as target for cancer therapy. Cancer Lett 2008, 266:37-52.

31. Sakamoto N, Oue N, Noguchi T, Sentani K, Anami K, Sanada Y, et al: Serial analysis of gene expression of esophageal squamous cell carcinoma: ADAMTS16 is upregulated in esophageal squamous cell carcinoma. Cancer Sci 2010, 101:1038-1044.

32. Davidson RK, Waters JG, Kevorkian L, Darrah C, Cooper A, Donell ST, et al: Expression profiling of metalloproteinases and their inhibitors in synovium and cartilage. Arthritis Res Ther 2006, 8:R124.
33. Kim S, Wong $P$, Coulombe PA: A keratin cytoskeletal protein regulates protein synthesis and epithelial cell growth. Nature 2006, 441:362-365

34. Alam H, Sehgal L, Kundu ST, Dalal SN, Vaidya MM: Novel function of keratins 5 and 14 in proliferation and differentiation of stratified epithelial cells. Mol Biol Cell 2011, 22:4068-4078.

35. Hosokawa M, Takehara A, Matsuda K, Eguchi $\mathrm{H}$, Ohigashi $\mathrm{H}$, Ishikawa $\mathrm{O}$, et al: Oncogenic role of KIAA0101 interacting with proliferating cell nuclear antigen in pancreatic cancer. Cancer Res 2007, 67:2568-2576.

36. Xu L, Geman D, Winslow R: Large-scale integration of cancer microarray data identifies a robust common cancer signature. BMC Bioinforma 2007, 8:275.

37. Turchi L, Fareh M, Aberdam E, Kitajima S, Simpson F, Wicking C, et al: ATF3 and p15PAF are novel gatekeepers of genomic integrity upon UV stress. Cell Death Differ 2009, 16:728-737.

38. Amrani YM, Gill J, Matevossian A, Alonzo ES, Yang C, Shieh JH, et al: The Paf oncogene is essential for hematopoietic stem cell function and development. J Exp Med 2011, 208:1757-1765

39. Zhao Y, Zhang J, Li H, Li Y, Ren J, Luo M, et al: An NADPH sensor protein (HSCARG) down-regulates nitric oxide synthesis by association with argininosuccinate synthetase and is essential for epithelial cell viability. $J$ Biol Chem 2008, 283:11004-11013.

40. Mun Gl, Kim IS, Lee BH, Boo YC: Endothelial argininosuccinate synthetase 1 regulates nitric oxide production and monocyte adhesion under static and laminar shear stress conditions. J Biol Chem 2011, 286:2536-2542.

41. Blanchet MR, Gold M, Maltby S, Bennett J, Petri B, Kubes P, et al: Loss of CD34 Leads To exacerbated autoimmune arthritis through increased vascular permeability. J Immunol 2010, 184:1292-1299.

42. Trempus CS, Morris RJ, Ehinger M, Elmore A, Bortner CD, Ito M, et al: CD34 Expression by hair follicle stem cells is required for skin tumor development in mice. Cancer Res 2007, 67:4173-4181.

43. Maltby S, Freeman S, Gold MJ, Baker JH, Minchinton Al, Gold MR, et al: Opposing roles for CD34 in B16 melanoma tumor growth alter early stage vasculature and late stage immune cell infiltration. PLoS One 2011, 6:e18160.

44. Berschneider B, Koenigshoff M: WNT1 inducible signaling pathway protein 1 (WISP1): A novel mediator linking development and disease. Int J Biochem Cell Biol 2011, 43:306-309.

45. Noseda M, Karsan A: Notch and minichromosome maintenance (MCM) proteins: integration of two ancestral pathways in cell cycle control. Cell Cycle 2006, 5:2704-2709.

46. Hsieh MJ, Chen KS, Chiou HL, Hsieh YS: Carbonic anhydrase XII promotes invasion and migration ability of MDA-MB-231 breast cancer cells through the p38 MAPK signaling pathway. Eur J Cell Biol 2010, 89:598-606.

47. Neri $\mathrm{D}$, Supuran $\mathrm{CT}$ : Interfering with $\mathrm{pH}$ regulation in tumours as a therapeutic strategy. Nat Rev Drug Discov 2011, 10:767-777.

48. Whitman S, Wang X, Shalaby R, Shtivelman E: Alternatively spliced products CC3 and TC3 have opposing effects on apoptosis. Mol Cell BiOl 2000, 20:583-593.

49. Paris S, Sesboue R, Chauzy C, Maingonnat C, Delpech B: Hyaluronectin modulation of lung metastasis in nude mice. Eur J Cancer 2006, 42:3253-3259.

50. Uchiyama Y, Sakaguchi M, Terabayashi T, Inenaga T, Inoue S, Kobayashi C, et al: Kif26b, a kinesin family gene, regulates adhesion of the embryonic kidney mesenchyme. Proc Natl Acad Sci USA 2010, 107:9240-9245.

51. Lucero $H$, Kagan $H$ : Lysyl oxidase: an oxidative enzyme and effector of cell function. Cell Mol Life Sci 2006, 63:2304-2316.

52. Rodriguez C, Rodriguez-Sinovas A, Martinez-Gonzalez J: Lysyl oxidase as a potential therapeutic target. Drug News Perspect 2008, 21:218-224.

53. Shiomi T, Lemaitre V, D'Armiento J, Okada Y: Matrix metalloproteinases, a disintegrin and metalloproteinases, and a disintegrin and metalloproteinases with thrombospondin motifs in non-neoplastic diseases. Pathol Int 2010, 60:477-496.

54. Hua $H$, Li M, Luo T, Yin Y, Jiang Y: Matrix metalloproteinases in tumorigenesis: an evolving paradigm. Cell Mol Life Sci 2011, 68:3853-3868.

55. Elberg G, Chen L, Elberg D, Chan MD, Logan CJ, Turman MA: MKL1 mediates TGF- $\beta 1$-induced $\alpha$-smooth muscle actin expression in human renal epithelial cells. Am J Physiol Renal Physiol 2008, 294:F1116-F1128.

56. Long X, Cowan SL, Miano JM: Mitogen-activated protein kinase 14 is a novel negative regulatory switch for the vascular smooth muscle cell contractile gene program. Arterioscler Thromb Vasc Biol 2013, 33:378-386.

57. Quaglino A, Salierno M, Pellegrotti J, Rubinstein N, Kordon E: Mechanical strain induces involution-associated events in mammary epithelial cells BMC Cell Biol 2009, 10:55 
58. Cox TR, Bird D, Baker AM, Barker HE, Ho MWY, Lang G, Erler JT: LOX-mediated collagen crosslinking is responsible for fibrosis-enhanced metastasis. Cancer Res 2013, 73:1721-1732.

59. Ringner M, Fredlund E, Hakkinen J, Borg $\AA$, Staaf J: GOBO: gene expressionbased outcome for breast cancer online. PLoS One 2011, 6:e17911.

60. Parker JS, Mullins M, Cheang MCU, Leung S, Voduc D, Vickery T, Davies S, Fauron C, He X, Hu Z, et al: Supervised risk predictor of breast cancer based on intrinsic subtypes. J Clin Oncol 2009, 27:1160-1167.

61. Fredlund E, Staaf J, Rantala J, Kallioniemi O, Borg A, Ringner M: The gene expression landscape of breast cancer is shaped by tumor protein p53 status and epithelial-mesenchymal transition. Breast Cancer Res 2012, $14: R 113$.

62. Minn AJ, Bevilacqua E, Yun J, Rosner MR: Identification of novel metastasis suppressor signaling pathways for breast cancer. Cell Cycle 2012, 11:2452-2457

63. Scharenberg MA, Chiquet-Ehrismann R, Asparuhova MB: Megakaryoblastic leukemia protein-1 (MKL1): Increasing evidence for an involvement in cancer progression and metastasis. Int J Biochem Cell Biol 2010, 42:1911-1914

64. Medjkane S, Perez-Sanchez C, Gaggioli C, Sahai E, Treisman R: Myocardinrelated transcription factors and SRF are required for cytoskeletal dynamics and experimental metastasis. Nat Cell Biol 2009, 11:257-268.

65. Descot A, Hoffmann R, Shaposhnikov D, Reschke M, Ullrich A, Posern G: Negative regulation of the EGFR-MAPK cascade by actin-MAL-mediated Mig6/Errfi-1 induction. Mol Cell 2009, 35:291-304.

66. Leitner L, Shaposhnikov D, Descot A, Hoffmann R, Posern G: Epithelial protein lost in neoplasm alpha (Eplin-alpha) is transcriptionally regulated by G-actin and MAL/MRTF coactivators. Mol Cancer 2010, 9:60.

67. Yoshio T, Morita T, Tsujii M, Hayashi N, Sobue K: MRTF-A/B suppress the oncogenic properties of v-ras- and v-src-mediated transformants. Carcinogenesis 2010, 31:1185-1193.

68. Brandt DT, Baarlink C, Kitzing TM, Kremmer E, Ivaska J, Nollau P, Grosse R: SCAI acts as a suppressor of cancer cell invasion through the transcriptional control of beta1-integrin. Nat Cell Biol 2009, 11:557-568

69. Throm Quinlan A, Sierad L, Capulli A, Firstenberg L, Billiar K: Combining dynamic stretch and tunable stiffness to probe cell mechanobiology in vitro. PLOS One 2011, 6:e23272.

70. Levental KR, Yu H, Kass L, Lakins JN, Egeblad M, Erler JT, Fong SFT, Csiszar K, Giaccia A, Weninger W, et al: Matrix crosslinking forces tumor progression by enhancing integrin signaling. Cell 2009, 139:891-906.

71. Lopez JI, Kang I, You WK, McDonald DM, Weaver VM: In situ force mapping of mammary gland transformation. Integr Biol (Camb) 2011, 3:910-921.

72. Cox TR, Erler JT: Remodeling and homeostasis of the extracellular matrix: implications for fibrotic diseases and cancer. Dis Model Mech 2011, 4:165-178.

73. Lu P, Weaver VM, Werb Z: The extracellular matrix: A dynamic niche in cancer progression. J Cell Biol 2012, 196:395-406.

74. Kessenbrock K, Plaks V, Werb Z: Matrix metalloproteinases: Regulators of the tumor microenvironment. Cell 2010, 141:52-67.

75. Nakagawa K, Kuzumaki N: Transcriptional activity of megakaryoblastic leukemia 1 (MKL1) is repressed by SUMO modification. Genes Cells 2005, 10:835-850.

76. Muehlich S, Wang R, Lee SM, Lewis TC, Dai C, Prywes R: Serum-induced phosphorylation of the serum response factor coactivator MKL1 by the extracellular signal-regulated kinase $1 / 2$ pathway inhibits its nuclear localization. Mol Cell Biol 2008, 28:6302-6313.

77. Muehlich S, Hampl V, Khalid S, Singer S, Frank N, Breuhahn K, Gudermann T, Prywes R: The transcriptional coactivators megakaryoblastic leukemia $1 / 2$ mediate the effects of loss of the tumor suppressor deleted in liver cancer 1. Oncogene 2012, 31:3913-3923.

78. Zaromytidou Al, Miralles F, Treisman R: MAL and ternary complex factor use different mechanisms to contact a common surface on the serum response factor DNA-binding domain. Mol Cell Biol 2006, 26:4134-4148.

79. Brellier F, Ruggiero S, Zwolanek D, Martina E, Hess D, Brown-Luedi M, Hartmann U, Koch M, Merlo A, Lino M, Chiquet-Ehrismann R: SMOC1 is a tenascin-C interacting protein over-expressed in brain tumors. Matrix Biol 2011, 30:225-233.

80. Schindelin J, Arganda-Carreras I, Frise E, Kaynig V, Longair M, Pietzsch T, Preibisch S, Rueden C, Saalfeld S, Schmid B, et al: Fiji: an open-source platform for biological-image analysis. Nat Methods 2012, 9:676-682.
81. Gentleman R, Carey V, Bates D, Bolstad B, Dettling M, Dudoit S, Ellis B, Gautier L, Ge Y, Gentry J, et al: Bioconductor: open software development for computational biology and bioinformatics. Genome Biol 2004, 5:R80.

82. Smyth GK, Speed T: Normalization of CDNA microarray data. Methods 2003, 31:265-273.

83. Schmittgen TD, Livak KJ: Analyzing real-time PCR data by the comparative CT method. Nat Protoc 2008, 3:1101-1108.

84. Livak KJ, Schmittgen TD: Analysis of relative gene expression data using real-time quantitative PCR and the 2(-Delta Delta C(T)) Method. Methods 2001, 25:402-408.

85. Aufderheide E, Ekblom P: Tenascin during gut development: appearance in the mesenchyme, shift in molecular forms, and dependence on epithelial-mesenchymal interactions. J Cell Biol 1988, 107:2341-2349.

86. Li DQ, Meller D, Liu Y, Tseng SCG: Overexpression of MMP-1 and MMP-3 by Cultured Conjunctivochalasis Fibroblasts. Invest Ophthalmol Vis Sci 2000, 41:404-410.

87. Min BH, Foster DN, Strauch AR: The $5^{\prime}$-flanking region of the mouse vascular smooth muscle alpha-actin gene contains evolutionarily conserved sequence motifs within a functional promoter. $J \mathrm{Biol}$ Chem 1990, 265:16667-16675.

doi:10.1186/1476-4598-13-22

Cite this article as: Gurbuz et al:: SAP domain-dependent Mkl1 signaling stimulates proliferation and cell migration by induction of a distinct gene set indicative of poor prognosis in breast cancer patients. Molecular Cancer 2014 13:22.

\section{Submit your next manuscript to BioMed Central and take full advantage of:}

- Convenient online submission

- Thorough peer review

- No space constraints or color figure charges

- Immediate publication on acceptance

- Inclusion in PubMed, CAS, Scopus and Google Scholar

- Research which is freely available for redistribution 